\title{
Calendaricities and multimodality in the Eastern Mediterranean cyclonic activity
}

\author{
I. Osetinsky and P. Alpert \\ Tel Aviv University, Dept. of Geophysics and Planetary Sciences, Israel \\ Received: 1 November 2005 - Revised: 27 March 2006 - Accepted: 27 March 2006 - Published: 29 June 2006
}

\begin{abstract}
Calendaricities, or the occurrence of weather anomalies on fixed calendar dates, are investigated for the Eastern Mediterranean (EM). The anomalies discussed here are the maxima and minima in the frequency of occurrence of the EM synoptic systems bearing rainfall. Those are mostly the Winter Lows passing over Cyprus en route eastward of the Ionian Sea where they are generated in situ or come to from N. Italy. The Winter Lows produce the rainfall over the central and northern EM areas, including Cyprus, Israel, Lebanon, NW Syria, W. Jordan. The southern EM areas, i.e. S. Israel and NE Egypt, get rainfall followed by floods due to the Winter Lows as well, and in addition, due to a small proportion of the mostly dry Red Sea Troughs that occasionally turn out to cause heavy rainfall. The analysis of the daily resolved data based on the NCEP/NCAR reanalysis is carried out. A comparison of two 28-yr periods, 1948-1975 and 1976-2003, different in global climatology, showed their similarity in the timing of peaks in EM cyclonic activity. The winter was found to have five maxima of cyclonic activity, centered on early February and nearly bell-shaped over their magnitudes. This supports the earlier hypotheses of multimodality in the EM rainfall. The Red Sea Troughs have their main peak of occurrence in the late October - early November, and their small rain-bearing proportion falls as well on this period of a year.
\end{abstract}

\section{Introduction}

1.1 Earlier works on calendaricities all over the globe

The existence of the atmospheric calendaricities, or tendency of the anomalies to occur on fixed calendar dates, was widely debated in the publications in the late 1940s - early 1960s

Correspondence to: I. Osetinsky

(isabella@cyclone.tau.ac.il) (in part referred to by Duncan et al., 1965). The "calendaricity" term was introduced by Brier et al. (1963) in order to avoid the confusion with "singularity". These authors rejected the existence of the calendaricities for the rainfall based on data over the entire United States. Then, Portig (1964) pointed that combining the data from too big an area suppressed the calendaricities. He held that calendaricities might be revealed when considering the data within a given region. Godfrey et al. (2002), discussing the existence of the January Thaw over the north-eastern U.S. stations during late January, "have failed to reject the null hypothesis that mere sampling variations have produced" this feature. However, Mapes et al. (2005), via an analysis of the Atmospheric Global Circulation Model simulations showed that the model is able to capture the intraseasonal rainfall peaks.

\subsection{Earlier works on the EM cyclonic activity timing}

In the EM region, the first studies on a timing of the cyclonic activity were carried out for Greece by Maheras (1988) and for Israel as will be detailed next. For Greece, Maheras was first to show by the use of the 5-day data averaged over 1950 1985 that there are more than one peak of cyclonic activity over Greece. For Israel, the common understanding that the rainfall course is unimodal (Elbashan, 1966; Goldreich, 1976; Katznelson, 1968), based on monthly averages of rainfall, was objected by Ronberg (1984) followed by Sharon and Ronberg (1988, hereafter SR88), suggesting the winter rainfall multimodality. Kutiel (1985) employed distribution of dry spells to further explore this multimodality. These studies were largely motivated by the 10-day averages of rainfall observations from the Hafetz-Hayim station (southern coastal plain, Israel) that surprisingly have shown a relatively dry period in the midwinter (Stiefel, 1981). Table 1b-d summarizes these results. 
Table 1. Dates in EM cyclonic activity (a) present study; (b) to (d) rainfall analysis: (b) following Sharon (1990) ${ }^{1}$, (c) by SR88, (d) "trimodal rainfall course" by Kutiel (1985).

\begin{tabular}{|c|c|c|c|c|c|c|c|c|c|c|c|}
\hline \multirow[b]{2}{*}{ Period } & \multicolumn{11}{|c|}{ Maxima and Minima } \\
\hline & Max I & Min I & Max II & Min II & $\begin{array}{l}\text { For (a) and (b) } \\
\text { Max III }\end{array}$ & Min III & Max IV & Min IV & Max V & Min V & Max VI \\
\hline \multicolumn{12}{|l|}{ (a) } \\
\hline $1948-2003$ & 18-19 Dec & $30 \mathrm{Dec}$ & 19 Jan & $25 \mathrm{Jan}$ & $6 \mathrm{Feb}$ & $21-22 \mathrm{Feb}$ & 1 March & 13-14 March & 20 March & 12 April & 19 April \\
\hline $1948-75$ & $19 \mathrm{Dec}$ & $30 \mathrm{Dec}$ & - & - & $1 \mathrm{Feb}$ & $19 \mathrm{Feb}$ & 3-4 March & 12-13 March & 19 March & 10 April & 18 April \\
\hline 1976-2003 & 18 Dec** $^{*}$ & 25 Dec* & $18 \mathrm{Jan}$ & $26 \mathrm{Jan}$ & $8-9$ Feb & $24 \mathrm{Feb}$ & $28 \mathrm{Feb}$ & 14 March & 20 March & 15 April & 22 April \\
\hline \multicolumn{12}{|l|}{ (b) } \\
\hline $1940-60$ & 27 Dec & 2 Jan & 14 Jan & $26 \mathrm{Jan}$ & 1 Feb & $17 \mathrm{Feb}$ & $28 \mathrm{Feb}$ & 11 March & 1 April & 11 April & - \\
\hline $1960-80$ & $11 \mathrm{Dec}$ & 2 Jan & 17 Jan & 31 Jan & $7 \mathrm{Feb}$ & $19 \mathrm{Feb}$ & 3 March & 11 March & 23 March & 1 April & 16 April \\
\hline (c) $* *$ & Max I & Min I & Max II & Min II & Max III & Min III & Max IV & & & & \\
\hline $1964-76$ & 21 Nov-20 Dec & 21 Dec-10 Jan & 11 Jan-10 Feb & 11 Feb-10 Mar & 11 March-31 March & 1-10 April & 11-30 April & & & & \\
\hline (d) & Max I & Min I & Max II & Min II & Max III & & & & & & \\
\hline 1958/9-77/8 & 10-20 Dec & 30 Dec-6 Jan & 20-30 Jan & 19 Feb-2 March & 4 March-29 Machr & & & & & & \\
\hline
\end{tabular}

Max and Min = maximum and minimum in (a) WL frequency of occurrence, (b) average daily rainfall, (c) frequency of stormy days. For (d), Max = minimum in the distribution of dry spells length, Min = maximum in this.

For 1976-2003, there are an additional maximum (on 1 January) after Max I and additional minimum (on 10 January) after Min I.

* 9 complete winters in between 1964-1976 were analyzed.

\subsection{Purpose of this study}

The present paper first introduces calendaricities for the peaks in the cyclonic activity over the EM based on the daily resolved semi-objective synoptic classification (Alpert et al., 2004a) for 1948-2003, by the use of the NCEP/NCAR reanalysis data (Kalnay et al., 1996). The temporal resolution (daily) is the finest and the period (56 years) is longest when compared to the earlier works. Two equally-long, 28-yr, periods are considered, 1948-1975 and 1976-2003. These periods happen to be very close to the 1946-1975 and 19762000 analysed by the Intergovernmental Panel on Climate Change (IPCC) Working Group I (Folland et al., 2001). The 1946-1975 was reported to be a period of little global temperature change. The 1976-2000 was a period with the greatest warming over the midlatitude Northern Hemisphere (NH) continents in winter, with a sharp increase in the North Atlantic Oscillation (NAO) positive phase during the $\mathrm{NH}$ winter, and a strong bias to the warm phase of El Niño. Following the IPCC report, the temperature trend for 1946-1975 over the nearly entire EM was slightly negative, while for 1976-2000, the whole EM experienced a significant warming (Ziv et al., 2005).

For all the classified synoptic systems, the average seasonal course of their frequency of occurrence was calculated as detailed by Alpert et al. (2004b). The technique described allows pointing on seasonal peaks in the cyclonic activity.

Section 2 will discuss the seasonal course of the Winter Lows (WL) frequency of occurrence that have 6 distinguished peaks, while Sect. 3 focuses on the Red Sea Troughs (RST), pointing on the factors that change this mostly dry synoptic system to rain-bearing.

\subsection{Methodology}

In the presented work, the classification methodology was used as described in Alpert et al. (2004a). In essence, the synoptic classification method, called "modified discriminant analysis", consists of the following steps: (i) a group of the regional experts-meteorologists manually classified a limited but representative set of the daily sea level pressure maps for the EM region at 12:00 UTC into 19 typical synoptic classes. This representative set, called "training set", consists of the daily maps for 1985 (a year selected for the only reason as being studied earlier) added with DJF 1991/92 (rainy-blessed winter), due to the high variety of the EM winter synoptic situations. Each of the 19 typical synoptic classes (circulation types) is characterized by its own set of the weather phenomena - temperature, amounts and duration of precipitation, wind vector, pressure, moisture etc. - over every locality within the EM region; (ii) The NCEP/NCAR reanalysis data including four meteorological fields - the geopotential height, temperature, and two horizontal wind components (zonal and meridional), at the $1000 \mathrm{hPa}$ pressure surface at 12:00 UTC for the 25 grid-points of the EM region $\left(30^{\circ} \mathrm{E}\right.$ to $40^{\circ} \mathrm{E}, 27.5^{\circ} \mathrm{N}$ to $37.5^{\circ} \mathrm{N}, 2.5^{\circ} \times 2.5^{\circ}$ resolution), were downloaded over 1948-2003. Thus, every daily synoptic situation was presented by a $4 \times 25=100$-dimentional vector; (iii) Each such $100 \mathrm{D}$ vector was a row for the common matrix including all days since 1 January 1948 until 31 December 2003. Each column of this matrix was the values of one meteorological field over one grid-point through all days at 12:00 UTC, for instance, temperature over $35^{\circ} \mathrm{E} / 32.5^{\circ} \mathrm{N}$. The training set was, naturally, a part of this matrix. Then, this matrix was normalized, separately for each column, 


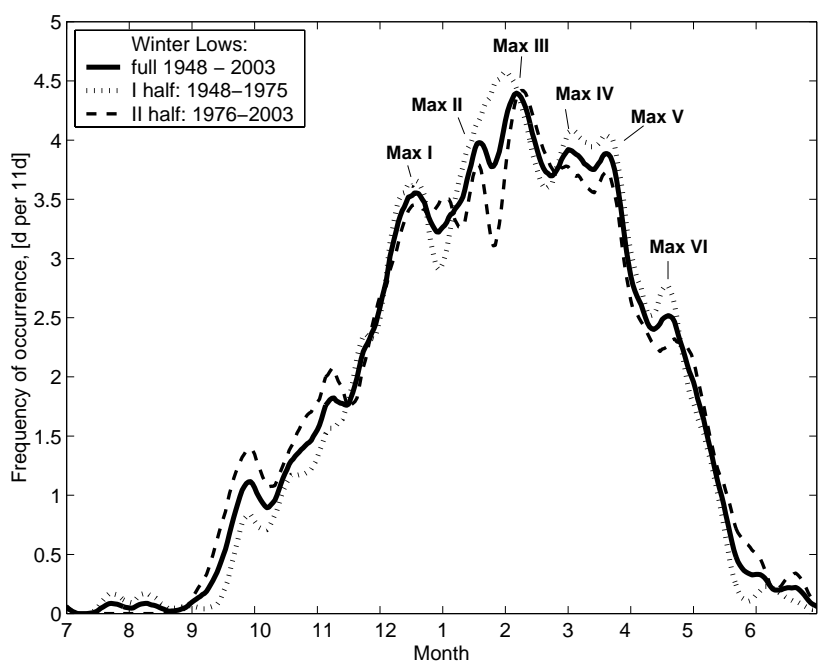

Fig. 1. Frequency of occurrence of the Winter Lows (WL), for 1948-2003 and the half periods, 1948-1975 and 1976-2003.

i.e. each entry $u$ was replaced with its departure from the column mean normalized by its standard deviation, i.e. with $(u-\bar{u}) / \sigma \mathrm{u}$, where $\bar{u}$ and $\sigma \mathrm{u}$ are a mean and a standard deviation, respectively, for given column; (iv) Using the normalized entries, for every given day (daily vector), the distances between it and every training day (training daily vector) were computed. A destination class for given day was defined to be the class, to which was belonging the training day with minimal distance to the given day.

Frequencies of the synoptic systems for the purposes of this work were calculated as described in Alpert et al. (2004b), i.e. by three steps: (i) a number of daily occurrences for given synoptic system within running 11-day interval since 1 January 1948 to 31 December 2003 was computed and assigned to the central day of this running interval, i.e. every day since 6 January 1948 until 26 December 2003 got its frequency value; (ii) these values were 7-day smoothed, i.e. every given day since 9 January 1948 until 23 December 2003 got its new value, being a weighed frequency of occurrence with a maximum weight of 7 for the 5 days straddling given day; (iii) all values obtained in the previous step were averaged for every calendar day over 1948-2003, or over its halves for the sake of comparison, i.e. 1948-1975 and 1976-2003, see next. (The date of 29 February was ignored at the last step, but had participated at the first two steps. Years 1948 and 2003 did not participate in averaging for the calendar days 1-8 January and 24-31 December, respectively). The time-spans of 11 and 7 days for the first two steps were selected after numerous computations aiming to find the optimal interval for smoothing insignificant oscillations and to catch the valuable information, for the goals of this work.

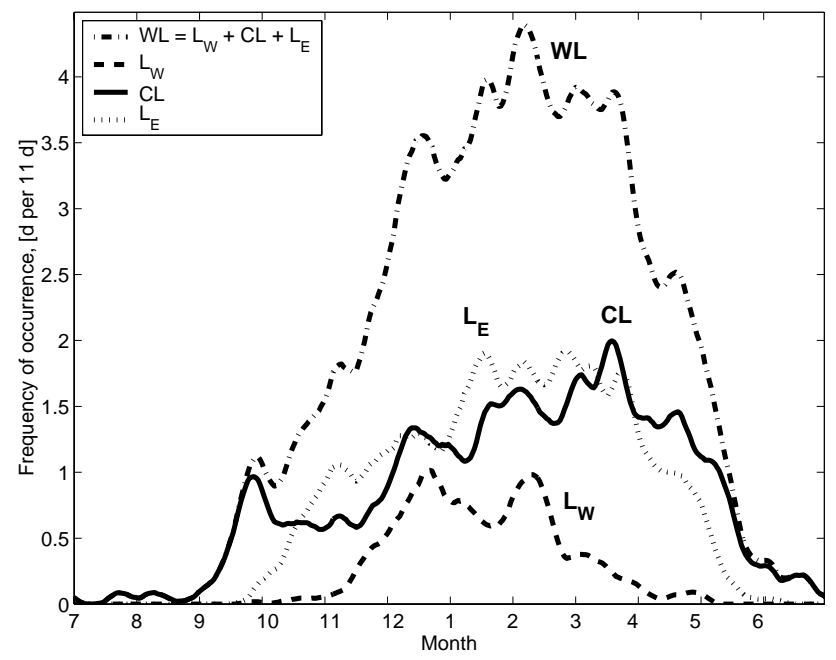

Fig. 2. Frequency of occurrence of the Winter Lows (WL) and their components: cold Lows to the west $\left(\mathrm{L}_{W}\right)$, Cyprus Lows (CL), and Lows to the east $\left(\mathrm{L}_{E}\right)$, for 1948-2003.

\section{The Eastern Mediterranean Winter Lows' seasonal course}

2.1 The Winter Lows' course and comparison with earlier studies

Earlier studies on the multimodality in the EM emphasized the rainfall in one or several stations in Israel (Stiefel, 1981; Ronberg, 1984; SR88; Kutiel, 1985). SR88 pointed out the close relationship of the rainfall multimodality with the number of the Cyprus Lows (CL) hitting the region as well as with the frequency of the upper troughs (Jacobeit, 1988) and the surface humidity of several stations in Israel. The monthly resolved seasonal variability of cyclonic activity is described by Alpert et al. (1990).

The current methodology of daily classification allows locating the exact dates for the maxima and minima in the cyclonic activity (Fig. 1). The Winter Lows' group include all types of Mediterranean Lows (Fig. 2) migrating eastward via the EM, as in the example shown in Fig. 3 (Sect. 2.2). Figure 4 compares between the dates in the cyclonic activity for two 28-yr periods (Sect. 2.3.2), and Fig. 5 focuses on the Cyprus Lows, the most important component of the Winter Lows.

Apart from the Max I to Max VI considered in this section in detail, Fig. 1 also shows two lower but notable WL peaks prior to Max I. The first one, in late September, consists only of the Cyprus Lows clearly peaking in this time for both 28yr periods (Fig. 5a). This WL peak is not associated with heavy rainfall and floods because all the late September CL are shallow as resulting from a combination of the decaying surface trough from the east and beginning activity of the upper trough. The second WL peak, in early November, is 


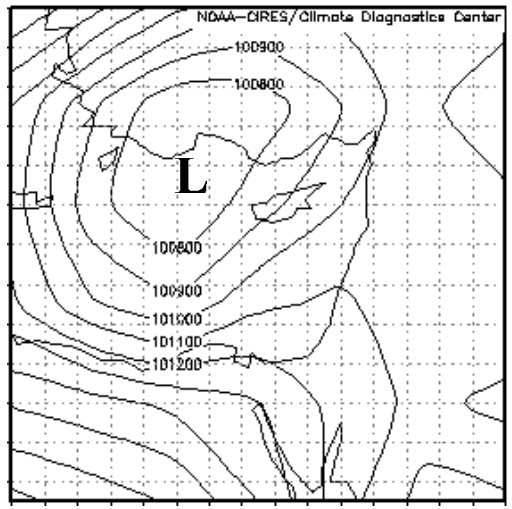

a) $10 \mathrm{Dec} 1961, \mathrm{~L}=1007 \mathrm{mb}$

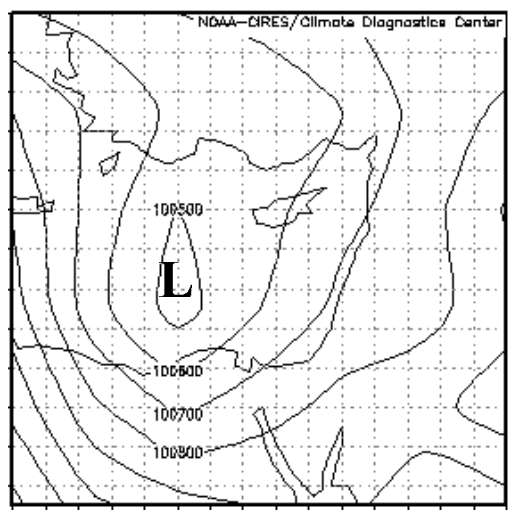

c) $12 \mathrm{Dec} 1961, \mathrm{~L}=1001 \mathrm{mb}$

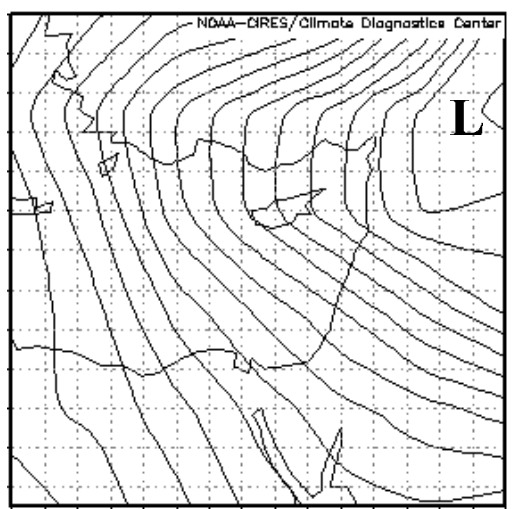

e) $14 \mathrm{Dec} 1961, \mathrm{~L}=999 \mathrm{mb}$

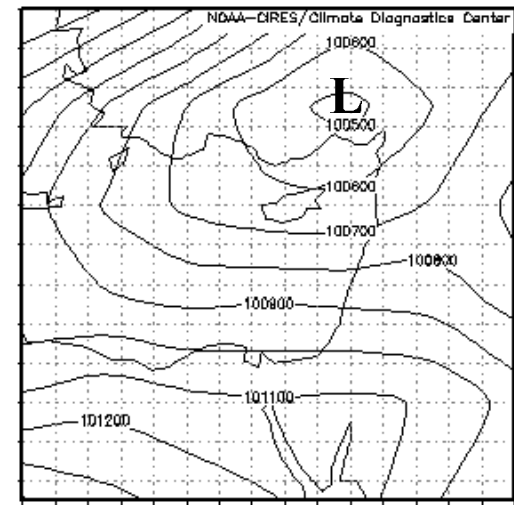

b) $11 \mathrm{Dec} 1961, \mathrm{~L}=1005 \mathrm{mb}$

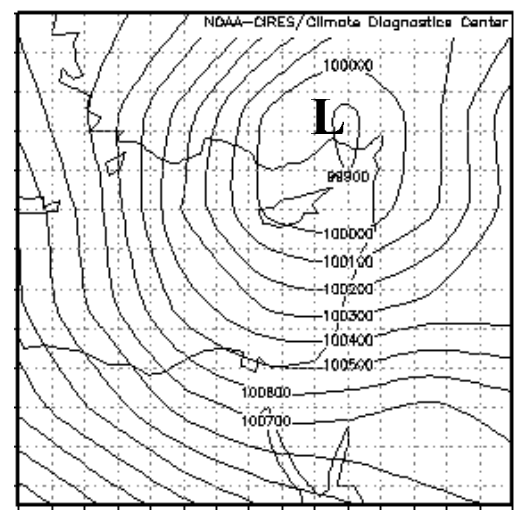

d) $13 \mathrm{Dec} 1961, \mathrm{~L}=999 \mathrm{mb}$

$\mathrm{L}$ - central pressure

Contour interval $1 \mathrm{mb}$

maps from http://www.cdc.noaa.gov/

Fig. 3. Example of an Eastern Mediterranean winter spell. Daily sea level pressure successive maps for 10-14 December 1961 at 12:00 UTC: (a) Lows to the west $\left(\mathrm{L}_{W}\right),(\mathbf{b}-\mathbf{d})$ Cyprus Lows $(\mathrm{CL})$, and (e) Lows to the east $\left(\mathrm{L}_{E}\right)$. Maps from NCEP/NCAR reanalysis at http://www.cdc. noaa.gov.

resulting from the active surface Red Sea Trough combined with the upper trough and considered next (Sect. 2.3.4 and Sect. 3).
Table 1a shows the WL maxima Max I to Max VI. The major WL maximum, Max III, reaches up to 4.5 days out of the 11-day interval (hereafter denoted as $x \mathrm{~d} /(11 \mathrm{~d})$ ). The WL frequency decreases significantly before Max VI on 18-22 April. The latter belongs to spring (Alpert et al., 2004b). The 


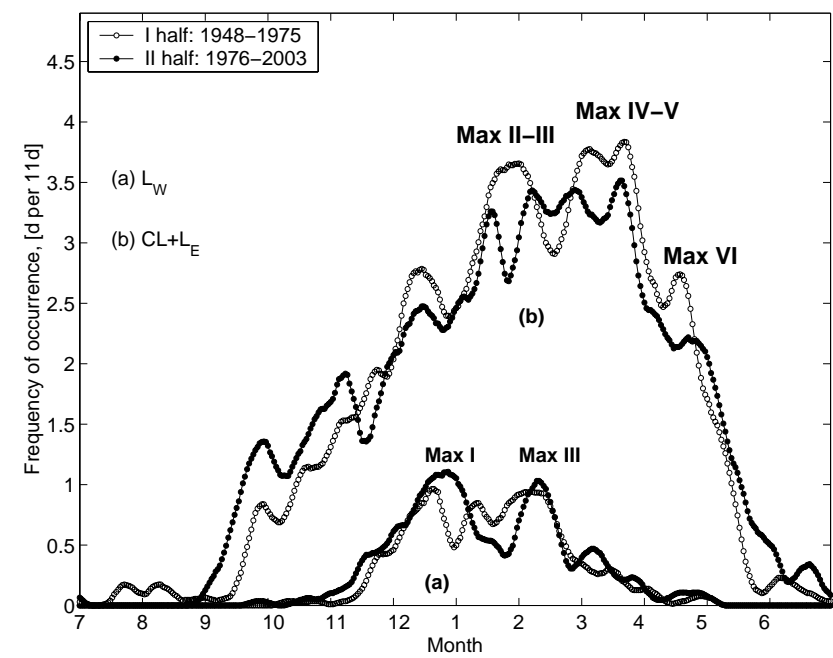

Fig. 4. Frequency of occurrence of the Winter Lows' components: (a) cold Lows to the west $\left(\mathrm{L}_{W}\right)$ and (b) Cyprus Lows (CL) + Lows to the east $\left(\mathrm{L}_{E}\right)$, compared for 1948-1975 (open circles) and 19762003 (black circles).

spring maximum Max VI (magnitude of $2.5 \mathrm{~d} /(11 \mathrm{~d})$ ) reaches up to $56 \%$ of the winter Max III.

Table 1a and Fig. 2 reveal some remarkable features of the WL seasonal course. The Max III seems to be a symmetrical center with regards to the secondary extremes. Table 1a shows that for the first half of winter, every minimum is closer to the previous maximum (with a distance of only about 1 to 1.5 weeks), while in the second half of winter, after Max III, this relation is in the opposite direction, i.e. each minimum is closer to the following maximum. The Max VI fits well this pattern (Table 1a; Fig. 2).

The Fast Fourier Transform was applied to the unsmoothed WL frequency of occurrence for the 128-day period from 16 December to 22 April. The periodicities of 44 to 7.5 days were found (Table 2). The dominant periodicity P2, of 22 days, fits a similar analysis by Sharon (1990) ${ }^{1}$ for rainfall. Sharon found the first harmonic of 24-25 days from February to April and fluctuation of 18-22 days from October to mid-December. The similar results for the two independent data-bases (synoptics and rainfall) support this frequency result.

The common 22- and 7.5-day periodicities (Table 2) for the two 28-yr periods confirms the same timing (assuming the same phase) in the course of the WL during a year, and consequently in the EM rainfall course.

\subsection{Components of the Winter Lows' group}

Figure 3 shows a typical sequence of the WL spell days over the EM; each is characterized by cyclonic activity in some parts of the EM.

\footnotetext{
${ }^{1}$ Sharon, D.: Further study of intra-seasonal variations in rainfall (personal communication), 1990.
}
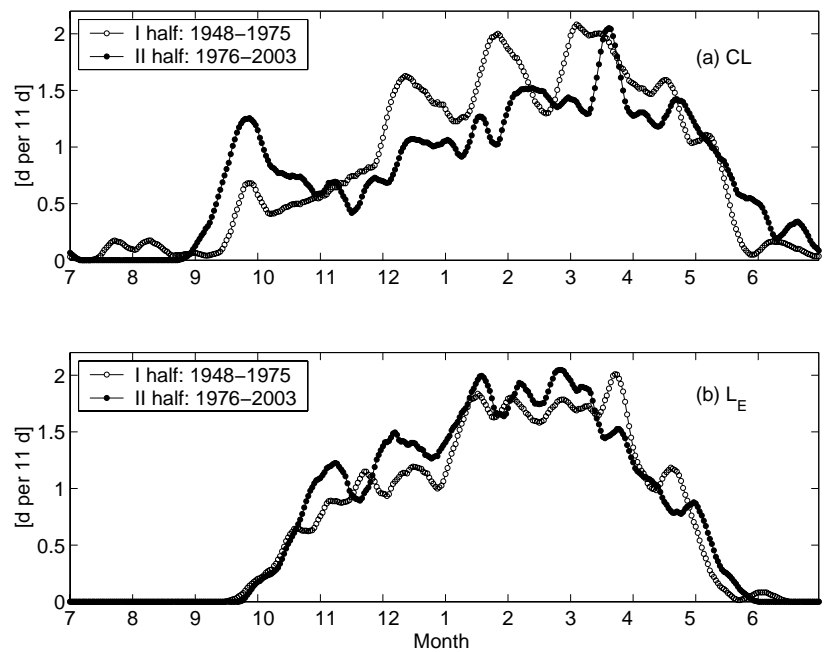

Fig. 5. Frequency of occurrence of the Winter Lows' components: (a) Cyprus Lows (CL) and (b) Lows to the east $\left(\mathrm{L}_{E}\right)$, compared for 1948-1975 (open circles) and 1976-2003 (black circles).

Table 2. Periodicities (days) in the course of the WL frequency of occurrence for 16 December-22 April.

\begin{tabular}{llllllll}
\hline Period & $\mathrm{P}_{1}$ & $\mathrm{P}_{2}$ & $\mathrm{P}_{3}$ & $\mathrm{P}_{4}$ & $\mathrm{P}_{5}$ & $\mathrm{P}_{6}$ & $\mathrm{P}_{7}$ \\
\hline Full & 44 & 22 & 16 & 13 & 11 & 9.4 & 7.5 \\
I half & 44 & $22-25$ & & & 11 & & 7.5 \\
II half & 33 & 22 & 16 & 13 & & $9.4-10$ & 7.5 \\
\hline
\end{tabular}

$\mathrm{WL}=$ Winter Lows.

Full $=$ full period, 1948-2003.

I half $=$ first half period, 1948-1975.

II half = second half period, 1976-2003.

The cold Low to the west $\left(\mathrm{L}_{W}\right)$ (Fig. 3a) is a deep lowpressure system often generated over N. Italy and located west to Cyprus. In this situation, it is common that N. Egypt, Cyprus and SE Turkey become rainy.

A Cyprus Low is obtained when a $\mathrm{L}_{W}$ moves eastward and is located near Cyprus, usually to the northeast of it. A center of the low pressure stays over the Cyprus area for several days, varying slightly in position and depth (Fig. 3b-d). Usually Israel, Lebanon, Syria, and SE Turkey are favourable for rain (Fig. 3b), but sometimes N. Egypt (Fig. 3c), or Israel, Lebanon, Syria, and N. Egypt together (Fig. 3d).

A Low to the east $\left(L_{E}\right)$ is a Cyprus Low leaving the EM eastward or north-eastward (Fig. 3e). In this case, N. Egypt and Israel, especially its southern part, may get rainfall.

\subsection{Factors affecting the Winter Lows' seasonal course}

When decomposing the Winter Lows' group back to the specific synoptic systems $\mathrm{L}_{W}, \mathrm{CL}$, and $\mathrm{L}_{E}$ (Figs. 2-4), some causes of the WL multimodality may be suggested. 


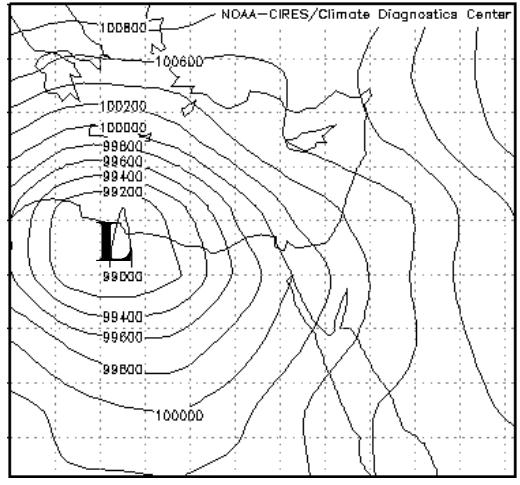

a) $15 \mathrm{Mar} 1998, \mathrm{~L}=990 \mathrm{mb}$

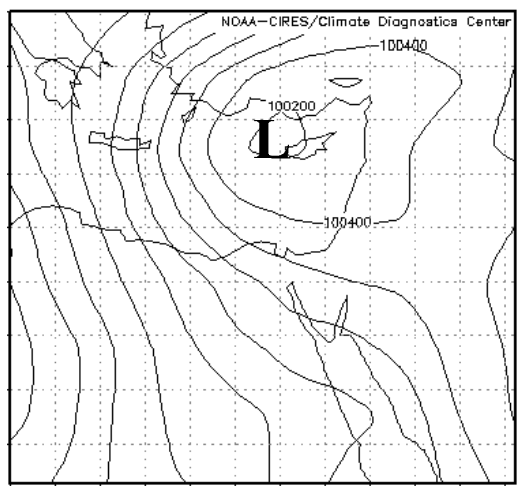

c) 17 Mar $1998, \mathrm{~L}=1002 \mathrm{mb}$

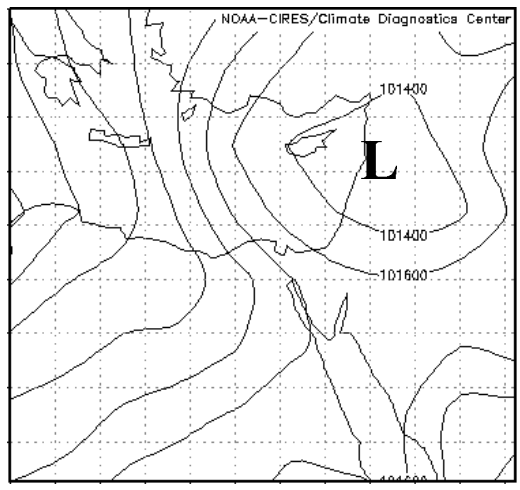

e) 19 Mar 1998, L=1014 mb

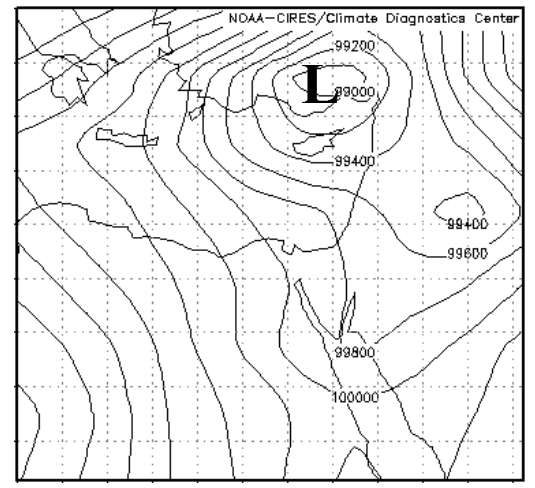

b) 16 Mar 1998, L=990 mb

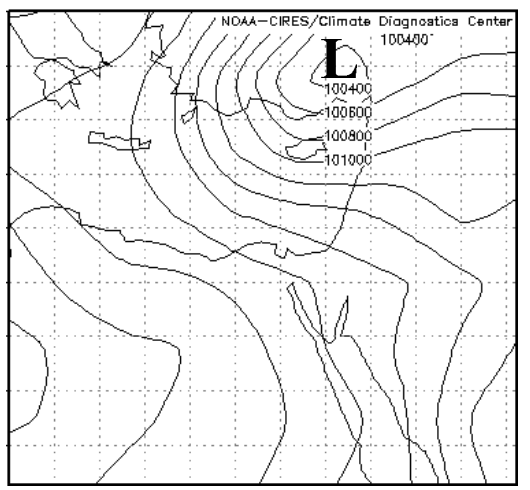

d) 18 Mar 1998, L=1004 mb

\section{$\mathrm{L}$ - central pressure}

Contour interval $2 \mathrm{mb}$

maps from http://www.cdc.noaa.gov/

Fig. 6. Example of a transition Sharav Low $\rightarrow$ Cyprus Low $\rightarrow$ Low to the east. Daily sea level pressure successive maps for $15-19$ March 1998 at 12:00 UTC: (a) Sharav Low (SL), (b-d) Deep Cyprus Lows (CL), and (e) Lows to the east ( $\left.\mathrm{L}_{E}\right)$. Maps from NCEP/NCAR reanalysis at http://www.cdc.noaa.gov.

\subsubsection{First factor - Cold Lows to the west}

The $\mathrm{L}_{W}$ are connected to Max I and Max III (Figs. 1, 2; Table 1). Their frequency peaks up to the value of $1 \mathrm{~d} /(11 \mathrm{~d})$ twice a year, on 19-23 December and on 9-10 February, and drops in between, i.e. in January, by $40 \%$, to $0.6 \mathrm{~d} /(11 \mathrm{~d})$, see Fig. 2. In general, the frequencies of the $\mathrm{L}_{W}$ during the cool season seem to be opposite to those in N. Italy based on the average monthly distribution of rainy days from where a
$\mathrm{L}_{W}$ often originates. For Genoa, these numbers are as follows: October - 14, November - 13, December - 12, January -13 , February -10 , March -12 , April -13 , May 14 (Weatherbase, 2005). A possible explanation for a larger number of the N. Italian cyclones moving eastward in December and February and less in midwinter (January) may be the varying intensity and direction of the westerlies depending on the changing depth and position of the NAO centers (Mächel et al., 1998). This is also expressed by the see-saw 
between west and east Mediterranean, the Mediterranean oscillation as first described by Conte et al. (1989) and later by Kutiel et al. (1996). All this holds for both 28 -yrs periods (Fig. 4a). The $\mathrm{L}_{W}$ maxima are on the 20-21 December and 1-12 February for 1948-1975 and on the 22-30 December and 18-19 February for 1976-2003.

\subsubsection{Second factor - stay over Cyprus}

The EM synoptic cyclones placed over Cyprus area are often delayed. This is due to the local topography of S. Turkey and Lebanon, heat and moisture fluxes from the sea surface (Alpert and Warner, 1986; Alpert et al., 1995), and cold continental polar air masses from Russia or southeast Europe (Barry and Chorley, 2003). An example is given in Fig. 3. The $\mathrm{L}_{W}$ position usually lasts only 1 day and is followed by a series of $\mathrm{CL}+\mathrm{L}_{E}$ days. As pointed above, we define the Cyprus Lows when mainly the northern and central parts of the EM get rainfall, and Lows to the east when it holds for the central and southern parts. Since this division has been somewhat conventional, and there are cases classified as belonging to $\mathrm{CL}$ while being only by a bit more distant of the $\mathrm{L}_{E}$ cases (Alpert et al., 2004a) and vice versa, we will consider a total of the $C L$ and $\mathrm{L}_{E}$ frequencies a contribution of delay into the EM cyclonic activity (Fig. 4b).

A first " $\mathrm{CL}+\mathrm{L}_{E}$ " maximum is on 15 December for both 28-y half periods. This date is 3 days earlier than Max I (18-19 December, Table 1a) and reaches up to $2.8 \mathrm{~d} /(11 \mathrm{~d})$ and $2.4 \mathrm{~d} /(11 \mathrm{~d})$ for $1948-1975$ and 1976-2003, respectively. Later, this sum rises very slowly up to $3.7 \mathrm{~d} /(11 \mathrm{~d})$ by Max V for full period. The $\mathrm{L}_{E}$ frequencies remain nearly constant during mid-January - early March, whereas the CL's tend to increase (Fig. 2). It is notable from Fig. 5a that, in spite of the larger magnitudes of the CL peaks for 1948-1975 when the NAO was weak, the timing of the peaks is nearly the same for both 28-y periods.

\subsubsection{Third factor - Sharav Lows}

Additional sources for the Max V on the 19-20 March (Fig. 2 and Table 1a) are the Sharav Lows (SL). These synoptic systems originate from the NE Africa. In March, due to a winter upper trough still presented over the EM, the Sharav Lows continue directly northward from NE Egypt to the Cyprus area and become Cyprus Lows. On the 19-20 March, Max V (Table 1a), the rising frequency of SL becomes about double the decreasing $\mathrm{L}_{W}$ frequency (Fig. 2). A famous example was the deep low-pressure spell on 15-19 March 1998 (Fig. 6; Alpert and Ganor, 2001). A SL loaded the desert dust over the EM and then turned out into a deep CL. The latter stayed over Cyprus for 3 days and afterwards moved eastward, then delayed further as a $\mathrm{L}_{E}$ for 2 more days. The case resulted in heavy rains and mountainous snow.

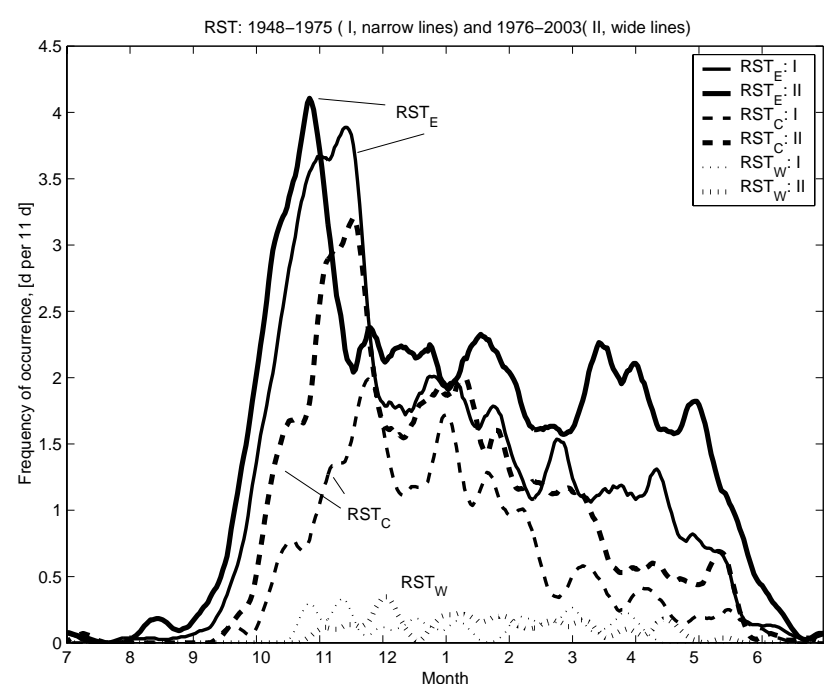

Fig. 7. Frequency of occurrence of the Red Sea Troughs (RST) by subtypes: RST with the eastern, central, western axis $\left(\mathrm{RST}_{E}\right.$, $\mathrm{RST}_{C}$, and $\mathrm{RST}_{W}$, respectively), compared for 1948-1975 (narrow lines) and 1976-2003 (wide lines).

\subsubsection{Fourth factor - RST}

A secondary peak of the Winter Lows in early November (Fig. 1) is mostly accounting for the Lows to the east whose November peak is especially notable for 1976-2003 (Fig. 7, detailed next). In about $10 \%$ of the Red Sea Trough cases, a northern part of a surface RST from the south becomes associated with an upper-tropospheric trough from the north, producing a Cyprus Low. Later, a Low to the east develops along with floods, mostly in the southern part of Israel (Kahana et al., 2004). During this period, WL spells enduring up to 6 days, are generated. Figure 2 shows that the $\mathrm{L}_{E}$ in early November is frequent as about twice CL. Early November is the only period in the course of a year that such a relation between $\mathrm{CL}$ and $\mathrm{L}_{E}$ exists, i.e. $\mathrm{L}_{E}(\%) \approx 2 \mathrm{CL}(\%)$. This holds for both climatologically significant periods of 1948-1975 and 1976-2003 (Fig. 5). The RST peak itself is discussed in detail next.

\section{Calendaricities in the Red Sea Troughs}

In this section, it will be shown for the first time that a significant bimodality exists in the seasonal course of Red Sea Trough. The RST frequency has a main peak in mid-autumn and a secondary peak in the winter.

The Red Sea Trough axis may be placed in one of three positions relative to the E. Mediterranean coast: (i) to the east of the EM eastern coastline $\left(\mathrm{RST}_{E}\right)$; (ii) over the coast $\left(\mathrm{RST}_{C}\right)$; (iii) to the west of it $\left(\mathrm{RST}_{W}\right)$. Figure 7 shows the average frequencies for the three RST types. The characteristic feature of the RST is the fast increase in their frequencies 
in late October. Then, the RST frequencies keep on high level during 2 to 3 weeks, until about mid-November. The major maximum in the RST frequency in late October - early November is well-known by the EM meteorologists. According to our daily data, the total RST frequency peaks on 2 to 15 November, in the middle of the EM autumn.

The major $\mathrm{RST}_{E}$ peak for 1976-2003 is on the 26 October. For 1948-1975, there is a "step" around this date, on 30 October-2 November, reaching up to $94 \%$ of its peak that is on 13-14 November. It is remarkable that the magnitudes of the $\mathrm{RST}_{E}$ maxima for two 28-y periods are very close to each other, having the values of $4.1 \mathrm{~d} /(11 \mathrm{~d})$ and $3.9 \mathrm{~d} /(11 \mathrm{~d})$, i.e. both around $4 d /(11 d)$.

The $\mathrm{RST}_{C}$ frequency peaks later than the $\mathrm{RST}_{E}$ by $1.5-$ 3 weeks: on the 24 November for first half period, 19481975, and on 17 November for the second one, 1976-2003. The magnitudes of the $\mathrm{RST}_{C}$ maxima are 2 and $3.2 \mathrm{~d} /(11 \mathrm{~d})$, respectively. These results are the first evidence that $\mathrm{RST}_{E}$ are more frequent than $\mathrm{RST}_{C}$. The $\mathrm{RST}_{W}$ frequencies are very low, but they appear in the same time span, from midOctober through April, for both half periods.

The probability of rainfall followed by floods is higher for $\mathrm{RST}_{C}$ than for $\mathrm{RST}_{E}$. Hence, given the $\mathrm{RST}_{E}$ intensity reaching up $35 \%$, on average, of the daily situations in late October and the $\mathrm{RST}_{C}$ 's $-22 \%$, on average, in midNovember, there are two adjacent dates with the very high probability of the autumn floods: the end of October, and mid-November. Between these dates, the probability of floods remains high. The flood period lasts $2-3$ weeks in the mid-autumn and separates the early dry and the late dry autumn.

The total RST frequencies (not shown) are peaking in the early November for both 28 -y periods. This is in spite of the clear differences between the RST frequency's magnitudes for two 28 -yr periods. The pronounced increase of the total RST frequencies for 1976-2003 at almost every calendar day, as compared to 1948-1975, explains the recent significant increase in the annual RST frequency. Alpert et al. (2004a) noted the nearly doubling in the average annual RST frequency from about 50 days in the 1950s to about 100 days in the 1990s. This could be associated with the recent rainfall decrease over most of the EM since RST is mainly associated with dry weather and winds from the eastern sector. It is interesting to note that the contribution of the $\mathrm{RST}_{C}$ to the total RST increase is dominant during the autumn and early winter while later (late winter and spring) it is the $\mathrm{RST}_{E}$ that becomes the major contributor.

The difference between the magnitudes of the November $\mathrm{RST}_{C}$ maxima for two 28 -yr periods is especially interesting: $3.2 \mathrm{~d} /(11 \mathrm{~d})$ for $1976-2003$ as compared to $2 \mathrm{~d} /(11 \mathrm{~d})$ for $1948-75$, that means 1.6 times increase. It explains the increased frequency of the catastrophic floods in S. Israel in the last decades (Kahana et al., 2004). In addition, as mentioned above, the November $\mathrm{RST}_{C}$ maxima for the second half period falls on 17 November that is by 1 week earlier then for the first half (24 November). It explains why for 1976-2003, the floods peaked on average by one week earlier then for 1948-1975.

The more frequent the RST the more in its absolute value a small rain-bearing proportion of the RST. This paradoxical reduction in total rain while increase in heavy is the topic of the paper by Alpert et al. (2002). Here, we suggest an explanation (at least partly) based on increase of RST situations for the EM.

\section{Conclusions}

The E. Mediterranean winter season is shown to be multimodal. The Winter Lows' frequencies have the main peak on the 6 February, in midwinter, and secondary maxima on 18-19 December, 19 January, 1 March, 20 March. There is also a pronounced spring WL maximum on 19 April. The five maxima of the winter cyclonic activity, centered on early February, are nearly bell-shaped over their magnitudes.

The Winter Lows produce the rainfall over the central and northern EM areas, including Cyprus, Israel, Lebanon, NW Syria, W. Jordan. The southern EM areas, i.e. S. Israel and NE Egypt, get rainfall followed by floods due to the Winter Lows as well, and in addition, due to a small proportion of the mostly dry Red Sea Troughs that occasionally turn out to cause heavy rainfall. The EM autumn synoptic system of the Red Sea Trough has one main peak in early November. This time has the highest probability for the catastrophic floods in the southern part of the EM.

The quite fixed dates for the majority of the maxima and minima in the EM cyclonic activity have been kept for two climatologically representative 28 -yr periods of 1948-1975 and 1976-2003, in spite of the significant differences in the global atmospheric-oceanic activity during the two periods. The most unexpected results are the strongly-kept calendar dates for the secondary maxima of cyclonic activity rather than for major ones, and during the transitional seasons rather than in the middle of the established winter. 


\section{Appendix A}

\section{List of acronyms}

$\begin{array}{ll}\text { CL } & \text { Cyprus Lows } \\ \text { DJF } & \text { December, January, February } \\ \text { EM } & \text { Eastern Mediterranean } \\ \text { IPCC } & \text { Intergovernmental Panel on Climate } \\ & \text { Change } \\ \text { L }_{E} & \text { Low to the east } \\ \text { L }_{W} & \text { cold Low to the west } \\ \text { Max } & \text { maximum frequency } \\ \text { NAO } & \text { North Atlantic Oscillation } \\ \text { NCAR } & \text { National Center for Atmospheric Re- } \\ & \text { search } \\ \text { NCEP } & \text { National Center for Environmental Pre- } \\ & \text { diction } \\ \text { NE } & \text { northeast } \\ \text { NH } & \text { Northern Hemisphere } \\ \text { NW } & \text { northwest } \\ \text { RST } & \text { Red Sea Trough } \\ \text { RST } \\ \text { RST }\end{array}$

Acknowledgements. This study was partly supported by the GLOWA-Jordan River grant of the Ministry of Science Culture and Sport, Israel and the Bundesministerium für Bildung und Forschung (BMBF). The NCEP Reanalysis data were provided by the NOAA-CIRES Climate Diagnostics Center, Boulder, Colorado, USA, from their Web site at http://www.cdc.noaa.gov/. We are especially thankful to D. Sharon, of the Hebrew University of Jerusalem, for providing us with much detail on earlier studies.

Edited by: A. Mugnai

Reviewed by: two referees

\section{References}

Alpert, P. and Ganor, E.: Sahara mineral dust measurements from TOMS - Comparison to surface observations over the Middle East for the extreme dust storm, 14-17 March 1998, J. Geophys. Res., 106, 18 275-18 286, 2001.

Alpert, P. and Warner, T. T.: Cyclogenesis in the Eastern Mediterranean, WMO/TMP Report Series, 22, 95-99, 1986.

Alpert, P., Neeman, B. U., and Shay-El, Y.: Intermonthly variability of cyclone tracks in the Mediterranean, J. Climate, 3, 1474-1478, 1990.

Alpert, P., Stein, U., and Tsidulko, M.: Role of sea fluxes and topography in eastern Mediterranean cyclogenesis, The Global Atmosphere-Ocean System, 3, 55-79, 1995.
Alpert, P., Osetinsky, I., Ziv, B., and Shafir, H.: Semi-objective classification for daily synoptic systems: application to the Eastern Mediterranean climate change, Int. J. Climatol., 24, 1001-1011, 2004a.

Alpert, P., Osetinsky, I., Ziv, B., and Shafir, H.: A new seasons definition based on the classified daily synoptic systems: an example for the Eastern Mediterranean, Int. J. Climatol., 24, 1013-1021, 2004 b.

Alpert, P., Ben-Gai, T., Baharad, A., Benjamini, Y., Yekutieli, D., Colacino, M., Diodato, L., Ramis, C., Homar, V., Romero, R., Michaelides, S., and Manes, A.: The paradoxical increase of Mediterranean extreme daily rainfall in spite of decrease in total values, Geophys. Res. Lett., 29(11), 1536, doi:10.1029/2001GL013554, 2002.

Barry, R. G. and Chorley, R. J.: Atmosphere, weather and climate, Routledge, 421 pp., 2003.

Brier, G. W., Shapiro, R., and Macdonald, N. J.: A search for rainfall calendaricities, J. Atmos. Sci., 20, 529-532, 1963.

Conte, M., Giuffrida, S., and Tedesco, S.: The Mediterranean Oscillation: impact on precipitation and hydrology in Italy, in: Proceedings of Conference on Climate and Water, V. 1, Publ. of Academy of Finland, Helsinki, 121-137, 1989.

Duncan, R. A., Rao, M. S., and Lokanadham, B.: The reality of calendaricities in Indian rainfall, J. Atmos. Terr. Phys., 27, 10551058, 1965.

Elbashan, D.: Monthly rainfall isomers in Israel 1931-1960, Israel J. Earth Sci., 15, 1-7, 1966.

Folland, C. K., Karl, T. R., Christy, J. R., et al.: Observed climate variability and change. Climate Change 2001: The Scientific Basis, edited by: Houghton, J. T., Ding, Y., Griggs, D. J., et al., Cambridge Univ. Press, 99-181, 2001.

Godfrey, C. M., Wilks, D. S., and Schultz, D. M.: Is the January Thaw a statistical phantom?, Bull. Amer. Meteorol. Soc., 83, 5362, 2002.

Goldreich, Y.: Regional variation of phase in the seasonal march of rainfall in Israel, Israel J. Earth Sci., 25, 133-137, 1976.

Jacobeit, J.: Intra-seasonal fluctuations of mid-tropospheric circulation above the eastern Mediterranean. Recent Climatic Change: A regional Approach, edited by: Gregory, S., Belhaven Press, Ch. 8, 1988.

Kahana, R., Ziv, B., Dayan, U., and Enzel, Y.: Atmospheric predictors for major floods in the Negev desert, Israel, Int. J. Climatol., 24, 1137-1147, 2004.

Kalnay, E., Kanamitsu, M., Kistler, R., et al.: The NCEP/NCAR 40-Year Reanalysis Project, Bull. Amer. Meteorol. Soc., 77, 437471, 1996.

Katznelson, J.: Rainfall in Israel as a basic factor in the water budget of the country, Meteorological Papers, A24, Israel Meteorol. Ser. (in Hebrew), 1968.

Kutiel, H.: The multimodality of the rainfall course in Israel, as reflected by the distribution of dry spells, Archives for Meteorology, Geophys., and Bioclimatol., B36, 15-27, 1985.

Kutiel, H., Maheras, P., and Guika, S.: Circulation indices over the Mediterranean and Europe and their relationship with rainfall conditions across the Mediterranean, Theor. Appl. Climatol., 54, 125-138, 1996.

Mächel, H., Kapala, A., and Flohn, H.: Behaviour of the centres of action above the Atlantic since 1881. Part I: Characteristics of seasonal and interannual variability, Int. J. Climatol., 18, 1-22, 
1998.

Maheras, P.: The synoptic weather types and objective delimitation of the winter period in Greece, Weather, 43, 40-45, 1988.

Mapes, B. E., Liu, P., and Buenning, N.: Indian monsoon onset and Americas midsummer drought: out-of-equilibrium responses to smooth seasonal forcing, J. Climate, 18, 1109-1115, 2005.

Portig, W. H.: A search for rainfall calendaricities, J. Atmos. Sci., 21, 462, 1964.

Ronberg, B.: An objective weather typing system for Israel: A synoptic climatological study, PhD thesis, The Hebrew University of Jerusalem, 126 pp., 1984.
Sharon, D. and Ronberg, B.: Intra-annual weather fluctuations during the rainy season in Israel. Recent Climatic Change: A regional Approach, edited by: Gregory, S., Belhaven Press, Ch. 9 , 1988.

Stiefel, S.: The Climate of Hafetz-Hayim 1970-1979. Israeli Min. of Agriculture (in Hebrew), 99 pp., 1981.

Weatherbase: http://www.weatherbase.com/, 2005.

Ziv, B., Saaroni, H., Baharad, A., Yekutieli, D., and Alpert, P.: Indications for aggravation in summer heat conditions over the Mediterranean Basin, Geophys. Res. Lett., 32, L12706, doi:10.1029/2005GL022796, 2005. 